\title{
UTAUT Model in Explaining the Adoption of Mobile Money Usage by MSMEs' Customers in Uganda
}

\author{
Paddy Mugambe \\ Uganda Management Institute, Uganda
}

Copyright $(2017$ by authors, all rights reserved. Authors agree that this article remains permanently open access under the terms of the Creative Commons Attribution License 4.0 International License

\begin{abstract}
Technology advancement has always been part of organizational efficiency and organizations take investment in technology as part and parcel of their annual plans. The increase in mobile telephone penetration in the emerging economies has presented new frontiers for technology to enhance Micro Small and Medium Enterprises' (MSMES) operations. Combining technological advancement in mobile connectivity with the low coverage of financial institutions/ services, has given rise to the phenomenon of mobile money which has in a way affected the MSMEs both positively and negatively. This paper uses both Meta-analysis and primary data to test to try and determine the extent to which the Unified theory of acceptance and use of technology (Venkatesh et al. 2003) can be used to explain the adoption of Mobile money services by the customers of Micro, small and medium enterprises in Uganda.
\end{abstract}

Keywords Unified Theory of Acceptance and Use of Technology (UTAUT), Mobile Money, Uganda, Micro Small Medium Enterprises (MSMEs)

\section{Introduction}

Technological connectivity positively influences a number of Business activities for business according to Statistics New Zealand [1]. A number of technological connectivity advances have been achieved globally but none has had a bigger impact than the mobile phone connectivity in the developing world as per World Economic Forum [2]. The increasing number of mobile phones in the developing world and the potential of the mobile platform to address business challenges present a lot of enthusiasm and opportunities for Micro, Small and Medium enterprises.

The mobile phone revolution has traversed different spheres of life in the developing world including Commerce, health and education according to Malhotra, A. Kanesathasan, A \& Payal P [3]. From the context of a small business, Mobile connectivity through mobile money can be used to facilitate money transfers, trading, as well as payments including salaries according to UNCTAD [4]. The evolution of mobile money is a result of the convergence of mobile technology and financial services to address a challenge of accessible banking services according to AfDB [5] and this has transformed economic activity and risk management by Small and Medium Enterprises. This is complemented by the migration of the working individuals from rural to urban areas or from their home areas to the areas that working opportunities are available as discussed by Egbuta [6] with a desire to maintain family ties in the African context. Previous money remittance avenues such as courier companies, use of buses or family and friends travelling to such rural areas have been replaced by mobile money services which are more reliable and less prone to risks.

Micro, Small and Medium Enterprises (MSMEs) have been defined in different ways from one region and country to another. As discussed by Kayanula and Quartey [7], what can be noticed clearly is that most definitions are based on factors such as number of employees, annual turnover and asset values. According to Ayyagari, Beck and Demirgüç-Kunt [8], the World Bank defines MSMEs as those enterprises having a maximum of 300 employees, generating a maximum of US\$ 15 Million as annual turnover and having a maximum of US\$ 15 million in value of Assets. The OECD, MSME and Entrepreneurship Outlook (2005) defines MSMEs as non-subsidiary, independent firms which employ fewer than a given number of employees varying across countries but the most frequent upper limit being 250 employees within the European Union. In the African context, the African Development Bank (ADB) defines MSMEs as enterprises with not more than 50 employees according to Tom and Van der Vaart, [9]. In Uganda, MSMEs are classified distinctively between small and medium enterprises. Small enterprises are defined as those employing a maximum of 50 individuals, with working capital of less than Uganda Shillings (UGX) 50 Million and turnover not exceeding Uganda Shillings (UGX) 50 Million per annum. Medium sized enterprises are those employing between 50 and 100 employees according to Kasekende and 
Opondo, [10]. One can then conclude that MSMEs in Uganda are those with a maximum of 100 employees.

From the above it's clear that in a number of economies world over, MSMEs form a vital part as argued by Peter and Naicker, [11] in terms of contribution to Gross Domestic Product (GDP), as a source of employment as well as a source of livelihood for citizens of these countries and as engines of economic development. According to the estimates by Ayyagari, Demirgüç-Kunt, and Maksimovic [8], nearly $95 \%$ of all firms worldwide are MSMEs and their total contribution to employment is at around $60 \%$ of all private sector employment. Within the East African countries, MSMEs have been the major contributors to these economies with $75 \%$ of all businesses being in the category of MSMEs in Government of Kenya [12] while in Uganda, MSMEs contribute up to $70 \%$ to the National GDP according to Obanda, [13].

\section{Background}

\subsection{Mobile Money Usage}

Mobile money is a term loosely used to refer to platform that allows money to be stored and transacted using the SIM (Subscriber Identity Module) as the key identifier rather than the common use of an account number with a financial institution as per Ndiwalana, Morawczynski, \& Popov [14]. According to IFC report [15], Mobile money refers to the use of mobile phones to perform financial and banking functions. Mobile money services were introduced in Uganda by Mobile Telephone Network (MTN) in 2009 following the success story of the same service in Kenya two year earlier. In a press release from MTN, by October 2015, the company estimated the number of mobile money transactions per month at 40 Million with a total value of UGX 1.8 trillion. According to Bank of Uganda, by June 2014, the number of registered Mobile money users (Just over 17,600,000) was more than three times that of the known account holders $(5,587,251)$ with financial institutions supervised by the same bank as reported by The Monitor [16]. According to Uganda Communication Commission, the growing popularity of Mobile money services has seen the number of registered mobile users rise from 5.7 million in 2011/12 to 12.1 million in 2012/13 up to the most recent record of 17.6 million in 2013/14 reflecting an average growth of $78 \%$ per annum. By end of December 2014, there were a total of 18.8 million mobile money registered users by Bank of Uganda [17] representing a growth rate of $32.4 \%$ in comparison with the previous year. In comparison with the year ending December 2015, a total of 21.1 million users had been registered. Below is a table showing the growth of Mobile money services in the country.

Indicated below is a graph showing the growth trend in the number of registered Mobile money users from the year mobile money services were introduced in the country to the most recent available data.
Table 1. Growth of mobile money transactions and customers

\begin{tabular}{|c|c|c|}
\hline Year & $\begin{array}{c}\text { Number of } \\
\text { transactions }\end{array}$ & $\begin{array}{c}\text { Number of registered } \\
\text { customers }\end{array}$ \\
\hline December 2010 & $28,816,000$ & $1,683,713$ \\
\hline December 2011 & $87,481,000$ & $2,879,968$ \\
\hline December 2012 & $241,728,000$ & $8,870,873$ \\
\hline December 2013 & $399,461,000$ & $14,243,379$ \\
\hline December 2014 & $496,249,000$ & $18,800,416$ \\
\hline December 2015 & $693,000,000^{*}$ & $21,100,000^{*}$ \\
\hline
\end{tabular}

*Estimated Figures

Source: Bank of Uganda

\subsection{Mobile Money Industry Infrastructure in Uganda}

The current infrastructure for Mobile money services has the Mobile Network Operator (MNOs) as the driving force in charge of both the design as well as instituting safeguards to ensure the safety of the user's funds. At the moment, the financial institutions regulator indirectly supervises the operations of the MNOs through the requirement for all operators to partner with a financial institution (Bank or Micro Deposit taking Institution (MDI)) or under its supervision for purposes of securing the funds associated with mobile money settlement services. This is the approach similar to the one adopted in Kenya with a view of promoting growth of the industry and innovation. As a way of creating clarity, the central bank has issued mobile money guidelines referred to as Bank of Uganda Mobile money guidelines 2013. Other than the Central Bank, the general operations of the MNOs are supervised by the Uganda Communication Commission which issues licences for the continued operations of the MNOs upon satisfaction of the minimum requirements. As far as mobile money services are concerned, the MNO delivers services to the final customers through a chain of wholesale and retail agents.

\subsection{Mobile Service Business Models and Services Offered in Uganda}

Mobile Money business in the country is dependent on all the actors in the structure. The MNO provides the platform for mobile money transactions to take place as well as contracting the network of agents both wholesale and retail. The bank controls the settlement accounts held by the various agents to ensure that the liquidity or cash flows are balanced in such a way that the liability of each agent does not exceed the amount on their accounts. The Wholesale agents act as intermediaries to the retail agents by accepting deposits from them and releasing virtual money on their settlement accounts. The retail agents are the primary contacts for the final consumers of the mobile money services. In terms of services, Mobile money provides a number of services including: Person to Person (P2P) transfers, Person to Business (P2B), Business/ Government to Person (B/G2P), Business to Business (B2B), Mobile 
Banking and International transfers. These services according to Gencer [18] can be broadly classified into three: Mobile payments, Mobile banking and Mobile finance.

\subsubsection{Mobile Payments}

Mobile payments include the various models of payments such as:

P2P which is person to person transfers involving one person transferring virtual money to another person both domestically as well as internationally according to Gencer [18]. This is the most common use of mobile money services within the country among the customers, according to the primary data obtained from interviewed users. The most common use being the sending and receiving of money to and from friends and family.

P2B/G is the Person to Business or Government, this involves an individual making payments to a business or Government. Within the country, a number of Business have through a partnership with the MNOs provided such an avenue for payments to be effected using mobile money. This payment form is common among utility providers, educational institutions and other merchants including retailers of goods or consumables. On the side of Person to Government, individuals can make payments to settle their tax and non-tax obligations to the state.

B/G2P is where it's either a business or the government effecting mobile money payment to a person. This takes the form of payment of salaries and/or allowances to an individual and in the case of Government, it has been implemented in payment of social benefits to the elderly.

B2B is for payment for goods and services between firms.

\subsubsection{Mobile Finance}

Products based on Mobile money have been developed by mainly Micro finance institutions to offer credit facilities to mobile money registered customers. Under credit, loans are disbursed and recoveries effected through Mobile money. The credit products normally move together with savings although savings can be another independent product of mobile money where a customer has an electronic wallet. As part of Mobile finance, MNO have partnered with Insurance companies provide insurance services to their registered customers who may not be on the mainstream insurance schemes.

\subsubsection{Mobile Banking}

MNOs in Uganda, through partnerships with mainstream financial institutions, offer Mobile banking services to their customers as indicated by Lwanga \& Adong [19]. The mobile banking services include taking deposits and withdrawal of cash either using the ATM or through mobile money agents as well as provision of an easy access to a registered customer to access information about their bank account transactions. Beyond these, the arrangement also allows payments to be effected by a customer using their mobile handset.

\subsection{Theoretical Background}

Explaining the acceptability and use of technology by different individuals has been a subject of debate among researchers with different models to explain this being fronted by Benbasat and Barki [20]. One of such models is the Unified Theory of Acceptance and Use of Technology (UTAUT) according to Venkatesh et al. [21]. This model is based on four important constructs of Performance expectancy, Effort expectancy, social influence and facilitating conditions being the direct determinant of the behavioral intention of the eventual technology user. Other than these four constructs, the relationship is moderated by individual differences in terms of Gender, Age, Experience and Voluntariness in Venkatesh et al. [21]. Upon review of UTAUT, Venkatesh et al. [22] dropped voluntariness as one of the moderating variables leaving only three constructs but also introduced three additional direct constructs as Hedonic motivation, Price value and habit in what they called UTAUT2. The theoretical backbone of this paper is the second model as extended in 2012.

According to Venkatesh et al [22], from the above model, Performance expectancy is defined as the degree to which using technology will provide benefits to the users; Effort expectancy is the degree of ease associated with the use of technology to the user; Social influence is the extent to which the user perceives those who are important to him or her believe they should use the technology; Facilitating conditions refers to the user's perception of the resources and support systems available to use the technology. In the extended version, Hedonic motivation is the pleasure derived from use of the technology; Price value is the cost and pricing structure associated with the use of the technology; Habit is the extent to which people tend to perform behaviors automatically because of learning. In the model, facilitating conditions, habit and behavioral intention determine the actual technology use while the remaining constructs influence behavioral intention.

\section{Methodology}

\subsection{Data Collection}

In undertaking this study, meta-analysis as per DeCoster [23] was adopted for secondary data collection and in the review of literature in support of the study. Data from differing sources was obtained, analyzed and reported in line with the Meta analysis principles. In addition to the Meta analysis, primary data was obtained from a sample of 400 mobile money registered customers using mobile money for transaction purposes. A purposive sample of the 400 customers registered customers were targeted using survey questionnaires with emphasis being on using mobile money for transaction purposes. Out of these, 354 customers were successfully reached and upon review and cleaning of the returned questionnaires, for completeness and integrity, a 
total of 321 responses were found to be appropriate for further analysis and indeed were analyzed.

\subsection{Data Analysis}

Data analysis for this study was based on the extended Unified Theory of Acceptance and Use of Technology (UTAUT2) according to Venkatesh et al [22] as expounded on under theoretical background above. The eight constructs under this model were coded as Performance Expectation (PE), Effort Expectancy (EE), Social Influence (SI), Facilitating Conditions (FC), Hedonic Motivation (HM), Price Value (PV), Habit (HA) and Behavioral Intention (BI).

Due to the numerous interactions that were to be tested, partial least Squares (PLS) was used to test the constructs in line with the original UTAUT studies of Venkatesh et al [21]. To complement these tests, factor loadings, composite reliability and Average variance extracted (AVE) were the basis for determination of convergent validities. Discriminant validity was assessed by using the square roots of AVE in comparison with the correlations between constructs as argued by $\mathrm{Yu}$ [24]. Lastly, internal consistency reliability (ICR) was the basis for measurement of reliability in line with Venkatesh and Zhang [25].

\section{Results}

This section shows a summary of the factor loading for the indictors that represent the constructs as well as a tables showing the internal consistency reliability (ICR), Composite reliability and average variance extracted AVE).

Results from factor loading indicated that in some cases as many as four factors out of four returned factor loading scores in excess of 0.7 which reading is regarded as adequate reliability and convergent validity as per Lee et al [26]. It's important to note that factors that reported less than 0.7 were eliminated on the reliability grounds and were not part of additional analysis.

Factors under performance expectancy, facilitating conditions and habit, returned four out of factor readings each in excess of 0.7 with the highest being at 0.842 and the lowest 0.719 . The remaining constructs under effort expectancy, Social influence, Hedonic Motivation, price value and behavioral intentions each returned three out of four factor readings with a factor reading in excess of 0.7 with the highest being 0.915 and the lowest 0.724 .

The highest reliability was returned under construct by social influence where respondents indicated that the environment within which they operate compels them to use mobile money services as result of the constant requests from their customers to avail them with mobile money services as an option for settlement of business transactions. Social Influence was closely followed by effort expectancy, which indicated that respondents found the use of mobile money services with low levels of effort in terms of ease of use, ease of sending and receiving money and low effort required by their customers, relatives and friends to access mobile money services most probably in comparison to the other financial service providers such as banks. The lowest reliability was returned under construct Price value where respondents indicated that the cost of mobile money services is still high with the overall factor reading of 0.706 in line with the services being affordable in comparison with other transaction channels especially the banks.

Table 2 shows the factor loading for the constructs where all the factors that made up the final loading had in excess of 0.7 which indicate adequate reliability and convergent validity according to Lee et al [25]. It's important to note that factors that reported less than 0.7 were eliminated on the reliability grounds.

The output from the factor loading for the final factors and ICR were as per the table below.

Table 2. ICR, composite reliability and AVE

\begin{tabular}{|c|c|c|c|}
\hline Construct & ICR & $\begin{array}{c}\text { Composite } \\
\text { Reliability }\end{array}$ & AVE \\
\hline $\begin{array}{c}\text { Performance } \\
\text { Expectancy (PE) }\end{array}$ & 0.772 & 0.724 & 0.628 \\
\hline $\begin{array}{c}\text { Effort Expectancy } \\
\text { (EE) }\end{array}$ & 0.902 & 0.866 & 0.740 \\
\hline Social Influence (SI) & 0.848 & 0.742 & 0.698 \\
\hline $\begin{array}{c}\text { Facilitating } \\
\text { Conditions (FC) }\end{array}$ & 0.756 & 0.827 & 0.625 \\
\hline $\begin{array}{c}\text { Hedonic Motivation } \\
\text { (HM) }\end{array}$ & 0.730 & 0.655 & 0.612 \\
\hline Price Value (PV) & 0.867 & 0.894 & 0.746 \\
\hline Habit (HA) & 0.782 & 0.862 & 0.782 \\
\hline $\begin{array}{c}\text { Behavioral Intention } \\
\text { (BI) }\end{array}$ & 0.864 & 0.830 & 0.645 \\
\hline
\end{tabular}

In line with the factor loading readings above, table 2 indicate that the composite reliabilities for each of the constructs under consideration were in excess of the threshold of 0.6 just like all AVE values that were in excess of 0.5 . These all supported reliability and convergent validity of the constructs. The same table also shows the ICRs with the minimum returned being 0.730 which is also above the threshold of 0.7 as additional support to the reliability. This was partly because of the earlier elimination of those factors whose factor readings were less than 0.7 as explained earlier in the introduction to this section of results. 


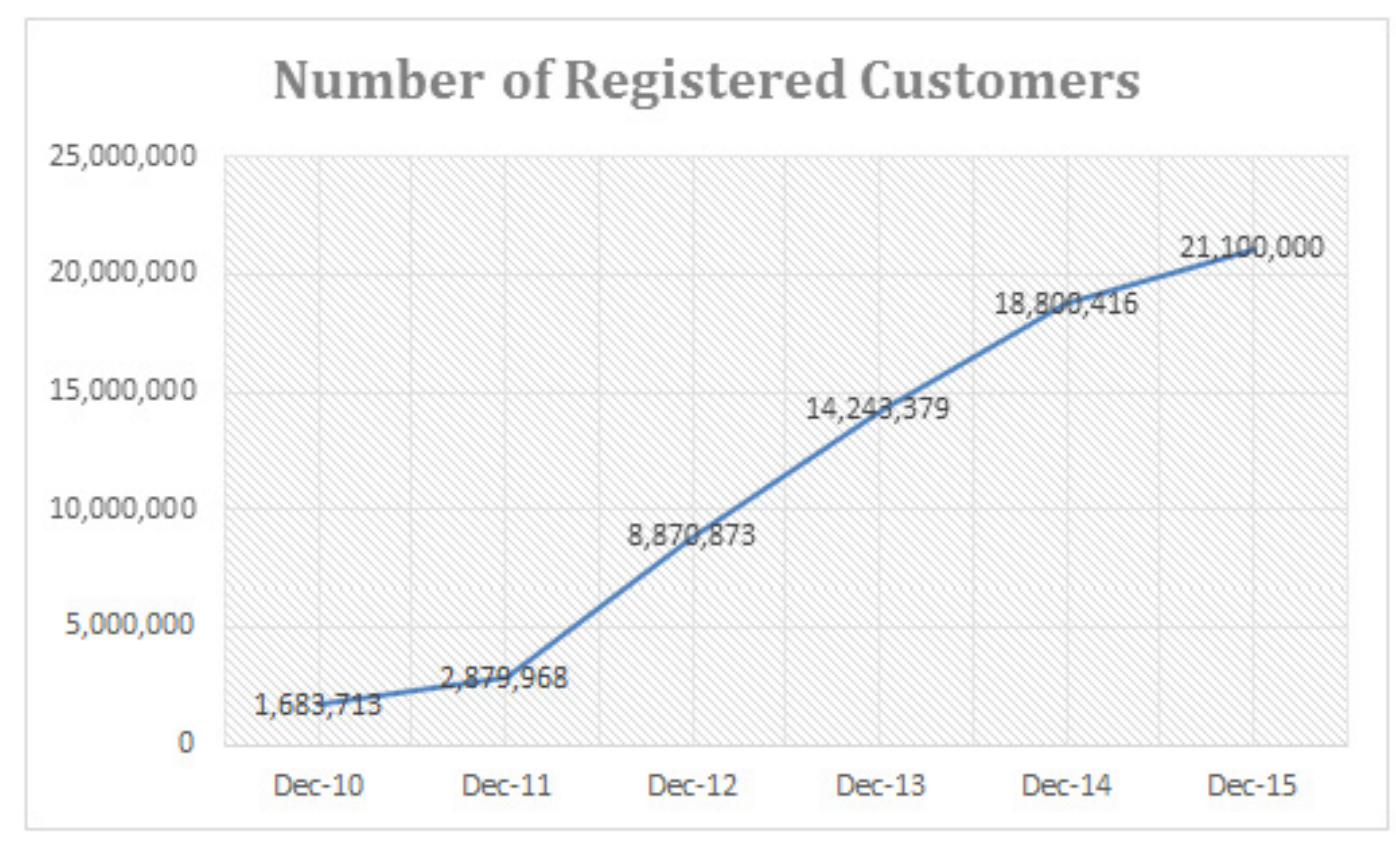

Source: Bank of Uganda

Figure 1. growth of mobile money registered customers

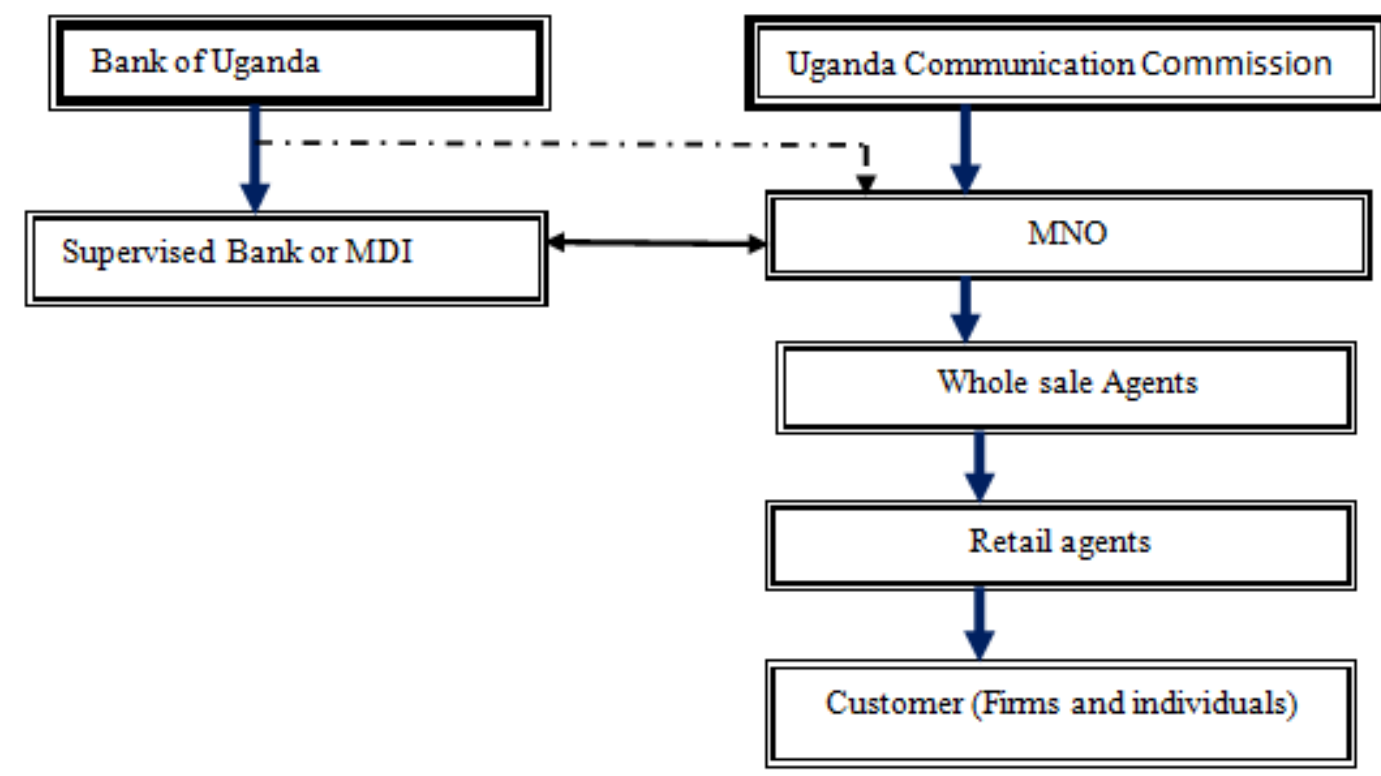

Source: literature review

Figure 2. structure of the mobile money industry

\begin{tabular}{|c|c|c|c|c|c|c|c|c|}
\hline \multicolumn{4}{|c|}{ Mobile Payments } & \multicolumn{3}{|c|}{ Mobile finance } & \multicolumn{2}{|c|}{ Mobile Banking } \\
\hline $\mathrm{P} 2 \mathrm{P}$ & $\mathrm{P} 2 \mathrm{~B} / \mathrm{G}$ & $\mathrm{B} / \mathrm{G} 2 \mathrm{P}$ & B2B & Credit & Savings & Insurance & Transactional & Informational \\
\hline
\end{tabular}

Source: Adapted from Gencer 2011

Figure 3. mobile money services by categorization 


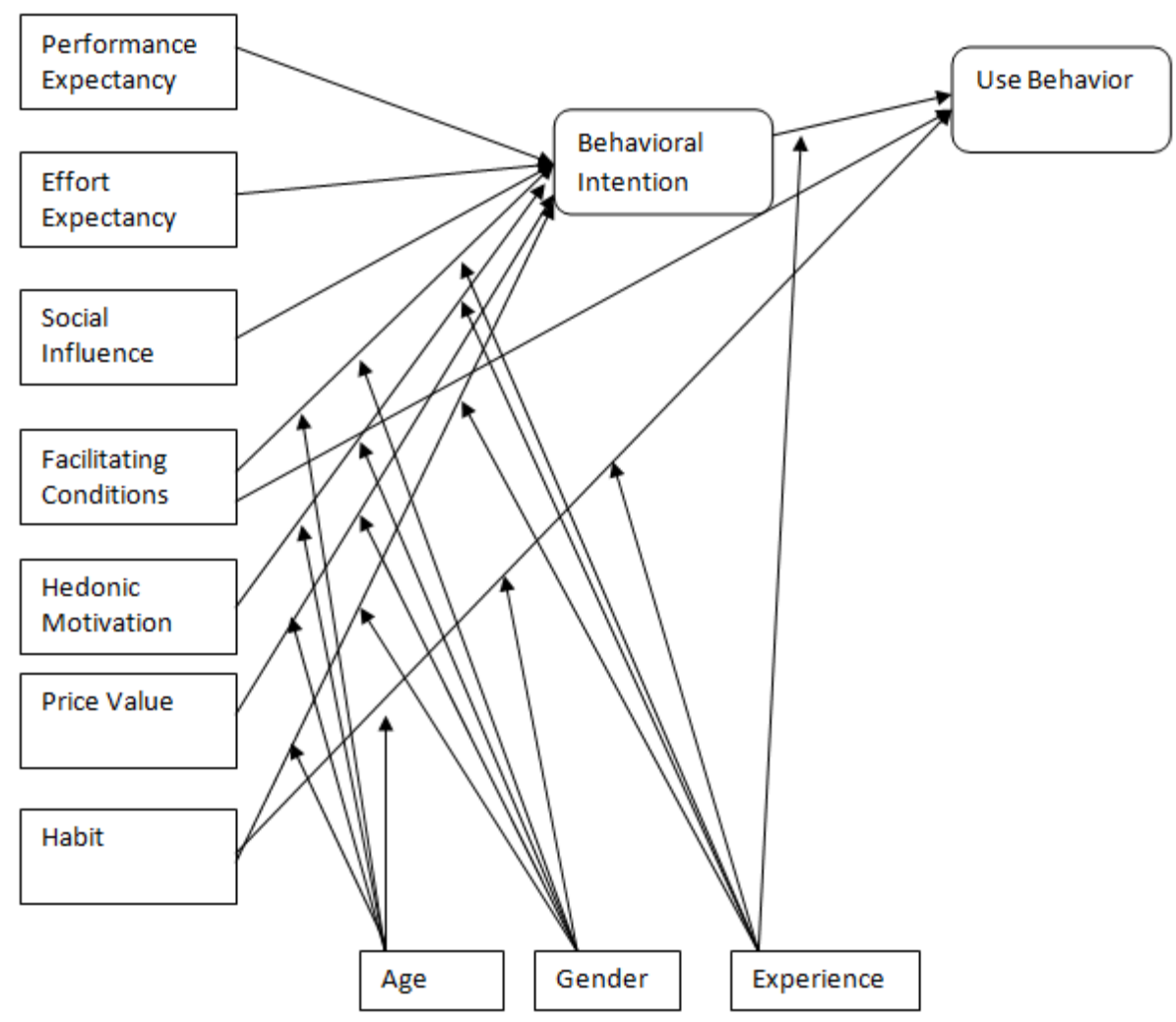

Source: Venkatesh Et Al., 2012

Figure 4. unified theory of acceptance and use of technology (utaut) 2

Table 3. descriptive statistics, correlations and square roots of AVE

\begin{tabular}{|c|c|c|c|c|c|c|c|c|c|c|c|}
\hline & Mean & SD & $\mathrm{PE}$ & EE & SI & $\mathrm{FC}$ & $\mathrm{HM}$ & PV & HA & BI & UB \\
\hline PE & 4.34 & 0.32 & 0.792 & & & & & & & & \\
\hline $\mathrm{EE}$ & 4.06 & 0.68 & $0.355^{* *}$ & 0.860 & & & & & & & \\
\hline SI & 4.60 & 0.36 & $0.425 * *$ & $0.365^{* *}$ & 0.835 & & & & & & \\
\hline $\mathrm{FC}$ & 4.15 & 0.56 & $0.340 * *$ & $0.550^{* *}$ & $0.325^{*}$ & 0.791 & & & & & \\
\hline HM & 3.89 & 0.89 & $0.335^{*}$ & $0.395^{*}$ & $0.235^{* *}$ & $0.315 * *$ & 0.782 & & & & \\
\hline $\mathrm{PV}$ & 4.01 & 0.62 & $0.265 * *$ & $0.350 * *$ & $0.225 * *$ & $0.350 * *$ & $0.405 * *$ & 0.864 & & & \\
\hline HA & 3.99 & 0.86 & $0.375^{* *}$ & $0.485^{* *}$ & $0.302 *$ & $0.465 * *$ & $0.405^{* *}$ & $0.465^{*}$ & 0.884 & & \\
\hline BI & 3.72 & 1.02 & $0.330 * *$ & $0.235^{* *}$ & $0.520^{*}$ & $0.250 *$ & 0.07 & $0.175^{* *}$ & $0.315^{*}$ & 0.803 & \\
\hline UB & 3.06 & 0.98 & $0.250^{* *}$ & $0.190 * *$ & $0.205^{*}$ & $0.265^{* *}$ & $0.250^{* *}$ & $0.325^{* *}$ & $0.300^{* *}$ & $0.585^{*}$ & NA \\
\hline
\end{tabular}

$* \mathrm{p}<0.05 ; * * \mathrm{p}<0.01$

Table 3 with descriptive statistics, correlation and square roots of AVE helps to assess discriminant validity. In the table, the second and third columns are for descriptive statistics, the following the diagonal figures are square roots of AVE and off-diagonal figures are correlations between constructs. From the table, the diagonal figures were in all cases greater than the off diagonal figures in the corresponding rows and columns which means that discriminant validity was supported.

Away from the tables, in terms of relationships, the results indicated a relatively strong relationship between the independent constructs and behavioral intentions with $\mathrm{R}$ being 0.792 while behavioral intention with the other two direct constructs of Facilitating conditions and habit were related with behavioral use, with $\mathrm{R}$ of 0.833 which also signifies a strong relationship.

In terms of explaining the change in one variable due to change in another, the combined constructs explained a change in Behavioral intention of $\mathrm{R}^{2}$ of 0.628 which means that they accounted for 0.628 of the change in behavioral intentions. Additionally Behavioral intentions with the other direct constructs accounted for a total of 0.694 of the change in Behavioral use.

Individually considering each construct as a standalone, Social influence $(\mathrm{R}=0.632)$ had the most significant effect on the mobile money usage by customers of firms in the country followed by habit $(\mathrm{R}=0.386)$ and facilitating conditions $(\mathrm{R}=0.384)$. This seems to be in agreement with some studies 
conducted in other countries by Sripalawat et al [27] but at the same time in disagreement with Nassuoro [28]) whose conclusion were that Facilitating conditions did not affect behavioral intention.

\section{Conclusions}

Technological advancement brings with it new way of completing different transactions and one those has been the advent of mobile money in the developing world. The ease with which this technology has been adopted by different user for business transaction purposes in away impacted on the customer base of MSMEs across different countries. The explanation for this adoption cannot be attributed to only the wide spread availability of mobile phone devices since mobile money services are not equally popular in countries with higher penetration of mobile phones. The study used UTAUT model to explain the adoption and usage of mobile money services by customers of that MSMEs in the country and a clear linkage was found in some of the constructs affect behavioral intention such as social influence, Habit and Facilitating conditions. On the other hand price value, Effort expectancy and hedonic motivation were found to be of the least significance.

\section{REFERENCES}

[1] Statistics New Zealand (2013). Strong connection between ICT and business-growth activities. Available from www.stats.govt.nz.

[2] World Economic Forum (2015), The Global Information Technology Report 2015. Available on http://www3.weforum.org/docs/WEF_Global_IT_Report_20 15.pdf accessed on December 12, 2015.

[3] Malhotra, A. Kanesathasan, A \& Payal P (2012), Connectivity How Mobile Phones, Computers and the Internet Can Catalyze Women's Entrepreneurship India: A Case Study retrieved from http://www.icrw.org/files/publicat ions/Connectivity-how-mobile-phones-computers-and-the-in ternet-can-catalyze-womens-entrepreneurship.pdf accessed on December 20, 2015

[4] UNCTAD (2012), Mobile Money for Business development in the East African Community, A Comparative Study of Existing Platforms and Regulations. Retrieved from http://unctad.org/en/PublicationsLibrary/dtlstict2012d2 en.p df accessed on December 12, 2015

[5] AfDB. (2013), Financial Inclusion and Integration through Mobile Payments and Transfer, Proceedings of Workshop on "Enhancing Financial Integration through Sound Regulation of Cross-Border Mobile Payments: Opportunities and Challenges". Retrieved from http://www.afdb.org/fileadmin/ uploads/afdb/Documents/Project-and-Operations/Financial_I nclusion_and_Integration_through_Mobile_Payments_and Transfer.pdf on December 14, $201 \overline{5}$
[6] Egbuta, O. C. (2013). Mobile Money Technology and the Quest for a Cashless Nigeria. Asian Transactions on Science \& Technology. Retrieved on March 18, 2016 from http://www.asian-transactions.org/Journals/Vol03Issue02/A TST/ATST-60303028.pdf

[7] Kayanula, D and Quartey P. (2000). The Policy environment for promoting small and medium-sized enterprises in Ghana and Malawi. Working series paper, 15. Manchester: Institute for Development Policy and Management, University of Manchester. Retrieved on March 19, 2016 from www.devinit.org/findev/Fd-wp15.doc

[8] Ayyagari, M., Demirgüç-Kunt, A. and Maksimovic, V. (2011), Small vs. Young Firms Across The World Contribution to Employment, Job Creation, and Growth, Policy Research Working Paper 5631 (The World Bank Development Research Group).

[9] Tom, G and van der Vaart. H. J. ( 2008). "Defining SMEs: A Less Imperfect Way of Defining Small and Medium Enterprises in Developing Countries. Retrieved on March 20, 2016 from

http://www.brookings.edu/ /media/research/files/papers/200 8/9/development\%20gibson/09_development_gibson.pdf

[10] Kasekende, $L$ and Opondo, $H$. (2003).Financing small and medium-scale enterprises (SMEs): Uganda's experience. BOU working paper. Retrieved on March 20, 2016 from http://www.aacb.org/IMG/pdf/FINANCING_SMEs.pdf

[11] Peter and Naicker (2013). Small medium micro enterprise business goals and government support: A South African case study. Accessed on Jan 15, 2016 from

http://www.usb.ac.za/sajbm/Journals/SAJBM\%20Vol\%2044 \%20Number\%204\%20December\%202013.pdf

[12] Government of Kenya (2009). Economic Survey Report. Nairobi: Government Printers. Hanna, N. K. (2010). Enabling enterprise transformation. Business and grassroots innovation for the knowledge economy. New York: Springer.

[13] Obanda, P. W. (2011), Small and medium enterprises (SMEs) and Public Procurement Contracts in developing countries. Accessed Jan 16, 2016 on http://www.ippa.org/IPPC5/Proceedings/Part9/PAPER9-5.p df

[14] Ndiwalana, A., Morawczynski, O., \& Popov, O. (2010). Mobile Money Use in Uganda: A Preliminary Study. Kampala: Makerere University. Retrieved on March 28, 2016 on

http://www.gsma.com/mobilefordevelopment/wp-content/up loads/2012/03/m4dmobilemoney.pdf

[15] IFC (2011), "Mobile Money Study 2011". Washington, DC. Accessed on march $26^{\text {th }}$ from http://www.ifc.org/wps/wcm/connect/fad057004a052eb88b2 3 ffdd29332b51/MobileMoneyReport-Summary.pdf?MOD= AJPERES

[16] The Monitor (2014): Registered Mobile money users hit the 17 million mark. Retrieved on March 3, 2016 from http://www.monitor.co.ug/Business/Registered-mobile-mone y-users-reach-17-million-mark/-/688322/2411528/-/rjcg2z/-/ index.html

[17] Bank of Uganda (2015) Annual supervision Report, Issue No. 5. Accessed on March 28, 2016 from https://www.bou.or.ug/ bou/bou-downloads/asr/2014/Dec/Annual-Supervision-Repo rt-2014-.pdf 
[18] Gencer, M. (2011). "The Mobile Money Movement: Catalystto Jump-Start Emerging Markets." Innovations: Technology, Governance, Globalization 6, no. 1: 101-17. Accessed on March 18, 2016 from file:/umisvr-03/umiuserdata\$/pmugambe/Documents/UMI $\% 20$ Work/Papers/Call\%20for\%20papers/New/Printed/To\%2 0Print/2014_sco_flac_the_mobile_money_movement.pdf

[19] Lwanga. M.M and Adong, A. (2016) A pathway to financial inclusion: Mobile Money and Individual Savings in Uganda, EPRC Research Series No. 127. Accessed on April 12, 2016fromhttp://ageconsearch.umn.edu/bitstream/2 $34553 / 2 / 127 \% 20$ A $\% 20$ pathway\%20to\%20financial\%20incl usion $\% 20-\% 20$ Mobile $\% 20$ money $\% 20$ and $\% 20$ individual $\% 2$ 0savings\%20in\%20Uganda.pdf

[20] Benbasat, Izak and Barki, Henri (2007) "Quo vadis TAM?," Journal of the Association for Information Systems: Vol. 8: Iss. 4, Accessed on March 12, 2016 from https://pdfs.semanticscholar.org/0766/d655ec78d789f9c8aa1 ce849c858b29546ad.pdf

[21] Venkatesh, V., Morris, M.G., Davis, G.B. and Davis, F.D. (2003). User acceptance of information technology: Toward a unified view, MIS Quarterly, 27(3), 425-478. Accessed on December 18, 2015 fromhttp://www.cob.calpoly.edu/ eli/Cl ass/p25.pdf

[22] Venkatesh, V., Thong, James Y. L., \& Xu, X. (2012). Consumer acceptance and use of information technology: Extending the Unified Theory of Acceptance and Use of
Technology. MIS Quarterly, (36), 157-178. Retrieved December 18, 2015

[23] DeCoster, J. (2004), Meta-analysis notes. Accessed on March 18, 2016 from http://www.stat-help.com/meta.pdf

[24] Yu, CS. (2012). Factors Affecting Individuals to Adopt Mobile Banking: Empirical Evidence from the UTAUT Model. Journal of Electronic Commerce Research, 13(2), 104-121

[25] Venkatesh, V. \& Zhang, X. (2010). The Unified Theory of Acceptance and Use of Technology: U.S. vs. China. Journal of Global Information Technology Management, 13 (1), 5-27.

[26] Lee, H.-J., Lim, H., Jolly, L.D. \& Lee, J. (2009) Consumer lifestyles and adoption of high technology products: a case of South Korea. Journal of International Consumer Marketing, 21 (2), 153-167

[27] Sripalawat, J., Thongmak, M., and Ngramyarn, A. (2011). M-banking in metropolitan Bangkok and a comparison with other countries. The Journal of Computer Information Systems, 51(3), 67-76.

[28] Nassuoro, A.B. (2012), Student acceptance of Mobile Learning for Higher Education. American Academic \& Scholarly Research Journal, Vol., pp.0-5. Retrieved on March 18, 2016 from http://naturalspublishing.com/files/published/ 57755 yw5 wvd3xw.pdf 